\title{
Configurations of Essential Factors Promoting China's Commercial Health Insurance: A Qualitative Comparative Analysis Based on Technology- Organization-Environment Framework
}

\author{
Xiuquan Huang \\ Macau Polytechnic Institute \\ Xiaocang Xu \\ Chongqing Technology and Business University \\ Tao Zhang ( $\boldsymbol{\sigma}$ taozhang@ipm.edu.mo) \\ Macau Polytechnic Institute
}

\section{Research Article}

Keywords: Commercial Health Insurance, Qualitative Comparative Analysis, Configuration, TechnologyOrganization-Environment Framework

Posted Date: July 13th, 2021

DOl: https://doi.org/10.21203/rs.3.rs-685397/v1

License: (c) (i) This work is licensed under a Creative Commons Attribution 4.0 International License.

Read Full License 


\section{Abstract \\ Background}

With the improvement in the living standards, China's health insurance under the social security system cannot satisfy people's diversified and high-level demands. Therefore, it is necessary to promote commercial health insurance $(\mathrm{CHI})$. This study identifies driving paths of $\mathrm{CHI}$ in China from configuration perspective.

\section{Methods}

This study innovatively constructs an analysis framework based on the Technology-OrganizationEnvironment theory to investigate the driving path of China's commercial health insurance. Using the data of 31 provincial regions of China in 2018, the fuzzy-set Qualitative Comparative Analysis (QCA) is employed for configuration analysis. For the robustness analysis of necessary condition, we also adopt the Necessary Condition Analysis.

\section{Results}

Three main findings are discovered. First, there is no necessary relationship between any condition and high or not-high performance of $\mathrm{CHI}$ and any condition. Nevertheless, there are three sufficient configurations, TOE strategy, GA-EA-CD strategy, and dual EA-CD strategy, to achieve high performance, and another three, TMC-EA-CD strategy, TI-EA strategy, and TI-TMC-EA strategy, to reach not-high performance. Second, technological conditions (TI and TMC) and EA are relatively more important than other conditions. Third, it is confirmed that the financial expenditure of government departments has a negative effect on the development of commercial health insurance.

\section{Conclusion}

There are configurations or pathways to achieve high or not-high performance of promoting $\mathrm{CHI}$ and key factors are identified successfully. Each region should choose the driving path suitable for itself, instead of making homogenization policies and replicating policies of regions with high performance. Besides, TC and EA as key factors should be overcome. Finally, the governments should formulate policies to systematically evaluate social insurance and $\mathrm{CHI}$ simultaneously and promote their coordinated development.

\section{Background}

For individuals and families, the uncertainty of disease occurrence is one of the most important risk factors to be considered, especially for low- and middle-income households[1]. To deal with the health 
risk, households can save money for health expenditure in advance[2], borrow privately or from a bank [3], restructure their jobs [4], and purchase related insurance[5, 6]. Insurance, as a delicate stabilizer of social life, is not only the basic but also the most effective means of risk management [7]. Since 2020, the Chinese government has established a universal medical insurance system including the Urban Employee Basic Medical Insurance (UEBMI), the Urban Resident Basic Medical Insurance (URBMI) and the New Cooperative Medical Scheme (NCMS) [8]. According to the China Statistical Year Book 2011, the universal medical insurance for urban and rural residents has improved greatly the ability of residents to bear disease, covering $95 \%$ of the total population, over 1.27 billion people by 2010 .

However, the medical insurance design under the social security system, based on the social and economic characteristics of large groups, does not have enough precision and is not flexible enough without having enough detailed options[9]. With the improvement of Chinese living standards, the basic medical insurance system cannot continue to meet people's diversified and high-level needs[10]. The World Health Organization (WHO) in 2011 forecast that the elderly ratio in China would reach $27 \%$ by 2050, another big challenge to the Chinese health insurance system [11]. In a mature insurance market such as America and Japan, the proportion of commercial health premium to life insurance premium income is about $30 \%$, while that in China of only about $20 \%$, which is a significant difference. Therefore, accelerating the development of commercial health insurance $(\mathrm{CHI})$ has become an important means to protect people's health. Meanwhile, China has given impetus to the market-oriented economic reforms to enhance the efficiency of the economy[12]. The medical security system is one of the Chinese government's important areas for market-oriented reform[13].

In recent years, the Chinese government has issued many relevant policies to vigorously support developing $\mathrm{CHI}$ and proposed to provide a variety of $\mathrm{CHI}$ options as an important pillar of the social security system. In addition, the market-oriented reforms decide that the promotion of $\mathrm{CHI}$, as market behavior, needs to make full use of the power of the market. It can be seen that $\mathrm{CHI}$ is affected by the government, market, and other factors. So, in the context of multiple factors, are there necessary factors? What is the driving path of the development of $\mathrm{CHI}$ ? What other paths are there? The answers to these questions will undoubtedly help the government to formulate more scientific and accurate policies.

The influencing factors of $\mathrm{CHI}$ promotion are divided into two types: demand and supply according to the main path. At present, China's $\mathrm{CHI}$ is facing a good market environment[14], so the supply is not restricted and its development is more driven by demand. Therefore, the relevant research on $\mathrm{CHI}$ promotion is mainly carried out from the perspective of demand. Influencing factors from demand can be divided into two categories. The first is by stimulating purchase intention including past health experiences[15], hygiene conditions[16], consumers' perception of risks[17], health or life expectations[18, 19], the social security system and residents' well-being[20]. The other is by increasing purchasing power and the main factors are the price of $\mathrm{CHI}[21]$, household income[22, 23], and taxation[24]. $\mathrm{CHI}$ is provided by profitseeking insurance companies, and their prices are calculated by scientific actuarial techniques according to multiple objective variables such as incident probability, treatment cost, and insurance fraud probability. The marginal cost of the insurance product is so small that the supply amount is not limited. 
The main factors affecting $\mathrm{CHI}$ promotion in supply come from the relevant characteristics of operating and agency insurance companies, such as the role played by insurance intermediaries[25], the difference of insurance products[26], and proportion of state-owned shares and the operation years[27].

The study introduces the Technology-Organization-Environment (TOE) theoretical framework proposed by LGFM Tornatzky and widely used in the field of technology adoption into the configuration analysis[28]. The TOE framework has also been flexibly applied in many other fields through the expansion of the technical connotation. Hue adopted TOE to explore the influence of these factors on the innovation decision of firms in Vietnam[29]. JK Nwankpa and JW Merhout examined three antecedents and the influence of digital investment on IT innovation, using TOE framework[30]. M Mkansi used a multi-case study qualitative approach to explore the strategies used by e-retail microbusinesses to potentially advance their e-business adoption[31].

This study employs fuzzy-set qualitative comparative analysis (fs/QCA), which is a new method based on set theory that has emerged in recent years. It is suitable for configuration analysis and has been used in many contexts. DP Hai employed the method to explain the public policy for innovative governance[32]. KH Huarng and THK Yu analyzed the impact of surge pricing on customer retention by the method[33]. C Llopis-Albert, JM Merigo, YJ Xu and HC Liao analyzed the level of satisfaction of stakeholders in the public participation process of water resources management, which is mandatory according to the EU Water Framework Directive[34]. MA Delmas and S Pekovic identified the configurations of relations between environmental practices and other management practices which can improve labor productivity[35].

There are three deficiencies in the current research about $\mathrm{CHI}$. Firstly, the existing research focuses on the independent effect of one factor, and the lack of consideration of the multi-factor synergistic effect of $\mathrm{CHI}$ promotion restricts the further understanding from the configuration perspective. The configuration perspective considers that multiple factors influence each other and depend on each other, and different permutations and combinations of factors can produce different effects, that is, multi-factor linkage synergistic matching effect. Second, there is still a lack of research on the promotion of $\mathrm{CHI}$ using TOE theory from the perspective of technology adoption. As a means of risk management, $\mathrm{CHI}$ can be regarded as a technology to deal with risks, and purchasing $\mathrm{CHI}$ can be regarded as the adoption and promotion of technology. TOE theory believes that the adoption of technology is mainly and simultaneously affected by three factors: technology, organization, and environment. Therefore, TOE framework is suitable for configuration analysis of the promotion of $\mathrm{CHI}$. Finally, the most existing literature using fs/QCA method does not remove the unreasonable hypothesis in the counterfactual analysis, so the results may deviate.

Given the above problems, this paper applies the fs/QCA based on TOE theory to study the synergistic matching effect of the multiple factors of $\mathrm{CHI}$ from the perspective of configuration, and explores the condition configuration and the driving paths of the promotion of $\mathrm{CHI}$, filling the existing research deficiencies and providing new analytical ideas for the field of $\mathrm{CHI}$. Besides, the study removes irrational 
assumptions in the counterfactual analysis of fs/QCA to make sure the results are more accurate and scientific. The data of 31 provincial regions in mainland China in 2018 is used in the study.

\section{Methods}

\section{A TOE framework for the promotion of $\mathrm{CHI}$}

Although the factors influencing the promotion of $\mathrm{CHI}$ are so many, there has been no widely accepted theoretical framework. Therefore, this paper creatively introduces the TOE framework in the field of technology adoption, regarding $\mathrm{CHI}$ as technology, and analyzing the technology application level, the development level of $\mathrm{CHI}$. The TOE framework focuses on the multi-level and linkage matching impacts of technology, organization, and environment on the technology promotion in society, a comprehensive analysis framework based on technology application scenarios. As a generic theory, TOE framework can

place a variety of factors and change them freely according to the research problems and background, so it has a wide range of applicability. The specific framework for analyzing the promotion of $\mathrm{CHI}$ constructed in this paper is shown in Fig. 1.

First, technological conditions include technological infrastructure ( $\mathrm{TI})$ and technological management capability (TMC). Technology factors mainly refer to the accessibility of technology and the ability to support innovation adoption and focuses on whether technology can match the organization and bring potential benefits. The technology application ability of the organization sets a wide range of restrictions for the organization and provides the possibility for the change of the technology. $\mathrm{Tl}$, closely related to the efficiency of technology promotion is like the infrastructure in economic development, which plays a key role in promoting the economy. TMC reflects the resource allocation ability of technology promoters, and also affects the promotion efficiency.

Secondly, organizational conditions include government attention (GA) and financial support (FS). The organizational factors are related to the characteristics and resources of an organization, including the structure, scale, and quantity of redundant resources. The implementation of policies and projects in China is significantly affected by the degree of concern of government departments. The more attention government pays, the more administrative resources support it receives, and things will be arranged to a higher priority. In addition, some FS, such as financial subsidies, tax preferences, will be helpful for the technology promotion.

Third, environmental conditions include environment adaptability (EA) and citizen demand (CD). Environmental factors include structure, demand pressure, institutional environment, and so on. EA measures the acceptance of technology by the local social environment and CD measures the potential market demand for the technology. These two can measure the difficulty of technology promotion from the perspective of the promotion environment.

\section{Fuzzy-set QCA procedures, methods, and data preparation}


To analyze the multi-level and linkage matching impact on the technology promotion based on the TOE framework, the study employed the fuzzy-set qualitative comparative analysis (fs/QCA). Qualitative comparative analysis includes three basic categories: clear set qualitative comparative analysis (cs/QCA), fuzzy set qualitative comparative analysis (fs/QCA), and multi-valued set qualitative comparative analysis (mv/QCA). In contrast to cs/QCA and mv/QCA, which are only suitable for class problems, fs/QCA can further handle the problem of degree change or partial membership. For this reason, fs/QCA has been widely used in relevant empirical studies in recent years. In the fields of organization, management, and education, more and more scholars have begun to apply the QCA method in other levels, especially in the meso-level research(organization level, social network, and collective actor level), and even in the micro-level research[36].

The method has four advantages to research this issue. First, QCA, case-oriented, analyzes problems from the perspective of the whole system and focuses on how the antecedents and conditions combine to produce results, which fully solves the problems of interdependence and causal complexity of variables in quantitative analysis[37, 38], because traditional quantitative analysis emphasizes the competition among variables and takes an isolated perspective to treat each variable. Although there is a moderating effect to analyze the effect of multiple conditions on the results, it strictly limits the number of conditions to not more than three [36]. Second, QCA method uses Boolean algebra and does not consider the omission of variables in the model [39]. Third, QCA is suitable for small, medium, and largescale samples, integrating the advantages of qualitative and quantitative analysis[36]. The advantage of qualitative analysis is that the case data is comprehensive and in-depth enough, but the generality is insufficient. The quantitative analysis can draw general conclusions from enough samples, but the information of individual cases is not in-depth enough, and there are some omissions. Finally, for the high and not-high performance of the promotion of $\mathrm{CHI}$, QCA can examine causal asymmetry[40].

\section{Measures and calibrations for set membership}

Calibration is a common operation step in physics, astronomy, and other natural science research. Natural science researchers adjust the instruments to calibrate the observed data so that they meet the corresponding standards in the discipline. Similarly, the calibration of original data is an indispensable step in QCA. Because QCA is based on the idea of set theory, uncalibrated data can only show the relative position of a variable. For example, this study can only know whether one country is more developed than another according to uncalibrated economic development data of two countries, but whether the countries belong to developed countries is difficult to judge. Specifically, both the United States and Vietnam are more developed than North Korea. Only with the standard of a developed country, this study know that the United States is a developed country, but Vietnam is not. Anchor points should be set for each variable according to the theoretical knowledge and three anchor points (fully in, crossover point, and fully in) are the most common[36]. This study uses logistic function to calibrate the original data to the values distributed between $0-1$, and the closer the value is to 1 , the higher the condition is. The direct calibration method, the most commonly used, was employed in this study, which could overcome the problems of lack of precise theoretical guidance and experience, and strong subjectivity to a certain 
extent [41]. As showed in Table 1, the $75 \%$ and $25 \%$ quantiles of variables were used as the thresholds for fully out and fully in, and the mean value of $75 \%$ and $25 \%$ quantiles were used as the thresholds for the crossover point.

This study measures the development of $\mathrm{CHI}$ using insurance density of $\mathrm{CHI}$ that is equal to per capita premium income. There are also other indicators, such as insurance depth, premium income, and other self-built indicators, but insurance density is most commonly used by scholars[42, 43]. This study assigns the anchors $0.18,0.244$, and 0.307 as the thresholds for fully out, crossover point, and fully in the high promotion of $\mathrm{CHI}$ set.

This study measures the technological infrastructure (TI) using the number of professional insurance intermediaries. The promotion of technology is inseparable from human resources, docking technology with practical demand. Driven by profits and their professionalization, insurance intermediaries play an important role in the promotion of $\mathrm{CHI}[25,44]$. The anchors 26,59 , and 92 were assigned as the thresholds for fully out, crossover point, and fully in the high $\mathrm{TI}$ set.

Technological management capability (TMC) was measured by the number of college students majoring in insurance. Education related to insurance determines professionalism, influencing the promotion efficiency of the technology, which reflected the investment and reserve of professional insurance human resources $[45,46]$. This study chooses $553.5,1000$, and 1446.5 as thresholds for fully out, crossover point, and fully in the high TMC set.

This study measures government attention (GA) using the days that the provincial government took to issue corresponding implementation policy documents for the guidance document that the central government issued in November 2014--Opinions of the general office of the State Council on accelerating the development of commercial health insurance. The document was an important landmark document to promote $\mathrm{CHI}$. Most provinces and municipalities have issued documents within two years, with Guizhou province's latest being in August 2018. It is reasonable to use December 30, 2018 as the deadline for this paper, because there are data calibration steps, which will not affect the scientific nature of the analysis results. The shorter the interval was, the more attention the provincial government paid to the promotion of $\mathrm{CHI}$. So, different from other indicators, the smaller the index is, the higher the membership score is. The thresholds for fully out, crossover point, and fully in the high GA set are in turn 1381,837 , and 293.

This study measures financial support (FS) using the proportion of medical health and family planning support in the local general public budget. The behavior that people purchase $\mathrm{CHI}$ is actually purchasing health and medical security services in the future [16]. The higher the expenditure on health care and family planning, the better the health and medical security services the insured can enjoy [47]. Indirectly, it improves the value of $\mathrm{CHI}$, which will affect the demand. The paper assigns $6.91,7.96$ and 9.01 as the thresholds for fully out, crossover point, and fully in the high FS set. 
This study measures environment adaptability (EA) using the urbanization rate, the proportion of the urban population. EA is a comprehensive measure of the acceptance of $\mathrm{CHI}$ by all sectors of society. Generally speaking, the higher the urbanization rate, the more mature the $\mathrm{CHI}$ market [48]. As a consumer behavior, purchasing $\mathrm{CHI}$ is influenced by many aspects of society, and the urbanization rate is just a comprehensive index to measure the acceptance[49]. This study assigns $53.38,59.52$ and 65.66 as the thresholds for fully out, crossover point, and fully in the high EA set.

This study measures citizen demand (CD) using the proportion of the elderly over 65 years old in the total population. $\mathrm{CD}$ reflects the potential demand for $\mathrm{CHI}$ in the current environment. The more the elderly population, the greater the demand for $\mathrm{CHI}[50,51]$. This study calibrates the scale anchors $9.655,11.246$, and 12.837 for fully out, crossover point, and fully in the high CD set.

\section{Analysis of sufficiency and necessity}

QCA is mainly used to analyze the sufficient or necessary conditions (in essence, set relations) between each condition and its configuration, and results. The necessary condition analysis is only for a single condition, and the sufficient condition analysis is for a single condition and configuration, which is the practice of most existing QCA studies.

The necessity analysis first and the sufficiency analysis later are beneficial to the counterfactual analysis in the configuration analysis. The key indicator to judge the necessity is consistency. When the consistency is greater than 0.9 , the condition can be considered as a necessary one $[52,53]$. In the analysis of necessary conditions, consistency refers to the proportion of outcome contained by condition, that is, the proportion of the intersection of outcome and the condition to the outcome. There are three key indicators to judge the sufficient configuration: consistency, the proportional reduction in inconsistency, and case frequency, for which critical values are set. According to the relevant literature, the critical values or threshold values of consistency and proportional reduction in inconsistency were set to 0.8 and 0.75 , respectively [54]. That of case frequency was set to 1 because the total number of cases in this study was small. Consistency in sufficient condition analysis refers to the proportion of condition contained by the outcome, that is, the proportion of the intersection of outcome and condition to the condition. Proportional reduction in inconsistency can help identify the relationship of simultaneous subsets, that is, one configuration is sufficient to both outcome and the negation of the outcome. Case frequency refers to the number of cases observed in a configuration. When three indicators reach their respective critical values, the configuration and the outcome constitute a sufficient condition relationship.

Different from most existing QCA literature, this study presents enhanced conservative solutions, intermediate solutions, and parsimonious solutions which means unreasonable assumptions would be removed in counterfactual analysis, ignored by most existing studies [52]. The unreasonable assumption is not equivalent to difficult logical remainder, and both easy and difficult logical remainder may contain unreasonable assumptions. There are three kinds of unreasonable assumptions in this study: first is that logic does not exist, such as pregnant man; the second is that one configuration is the sufficient condition of the outcome and negation of the outcome; the third is the configurations that are the necessary 
condition of the outcome and sufficient condition of negation of the outcome simultaneously [55, 56]. In the counterfactual analysis, this study excludes the unreasonable hypothesis from the logical remainder to make the results more scientific and reasonable.

The research results are presented following the form commonly adopted in the current literature using QCA. Specifically, the symbols and $\bigotimes$ represent the presence and absence of the core condition respectively, while the smaller symbols $\bullet$ and $\otimes$ with the same shape represent the presence and absence of the peripheral condition, and the blank represents the presence or absence of conditions does not matter. Core conditions are those conditions present in both parsimonious solutions and intermediate solutions, while peripheral conditions are those only present in intermediate solutions. In the process of counterfactual, TI, TMC, EA and CD are set as presence for the outcome of high performance of promotion of $\mathrm{CHI}$. Due to the limitation of the Barrel Principle and the lack of data calibration accuracy, the configuration of an outcome is complicated, so only EA is set as absence for the outcome of the nothigh performance of promotion of $\mathrm{CHI}$, a relatively conservative way.

\section{Necessary condition analysis (NCA).}

The paper adopts a new method, Necessary Condition Analysis (NCA), to analyze the necessary conditions, strengthening the robustness of necessary conditions for QCA analysis [57]. QCA can identify the necessary relationship, but it only qualitatively states whether a condition is necessary or unnecessary for an outcome, and does not quantitatively reflect the degree of necessity, that is, to what extent a condition is a necessary condition for an outcome [58]. The fuzzy set change is not only yes or no, but also includes detailed membership scores, which makes the combination of NCA and fs/QCA more valuable. NCA can not only identify whether a specific condition is a necessary condition for a certain outcome but also analyze the effect size, called the bottleneck level, of the necessary condition, which means the lowest level of necessary conditions to produce a specific result. The larger the effect size is, in the 0-1 range, the larger the effect is. In the NCA, the necessary conditions need to meet two requirements: the effect size is not less than 0.1 , and the Monte Carlo simulation permutation test of the effect size is significant [59]. The study employs both Ceiling regression (CR) and Ceiling envelopment (CE) to generate the upper bound function, comparing two results for robustness.

\section{Data source}

This study selects the provincial data of 31 provinces in China in 2018 for analysis. The development of China's commercial insurance is unbalanced among 31 provincial regions. For example, according to the 2016 data issued by the China Insurance Regulatory Commission (CIRC), the top 10 provinces in premium income are mostly in economically developed areas, with the total premium accounting for about $70 \%$ of the total. But, the last $30 \%$ of provinces' premium income account for less than $10 \%$ of the total. In addition, the social and economic development of China's provinces is not balanced. The existence of this phenomenon is beneficial to the observation of various combinations of conditions and 
meets the need for research. The data of this paper comes from China Statistical Yearbook, China Insurance Yearbook, and China Stock Market \& Accounting Research Database.

Table 2 and Table 3 show the results of necessity condition analysis in fs/QCA and NCA, respectively. It can be seen from Table 2 that all the consistencies are less than 0.9 , that is, all conditions and the negations of conditions do not constitute necessary conditions for the outcomes of high performance and not-high performance of $\mathrm{CHI}$. Table 3 shows no conditions can meet the two requirements in $\mathrm{CE}$ and CR except EA. But EA's effect size using CE is 0.135 , just a little more than the threshold value, 0.1 . Although its consistency in fs/QCA is only a little less than 0.9 , this study conservatively believe that the necessary conditions do not hold. This proves that the promotion mechanism of $\mathrm{CHI}$ is complex, and the explanatory power of a single factor is weak.

\section{Results}

\section{Analysis of necessary conditions}

\section{Analysis of sufficient condition}

This study analyzes the configurations of high and not-high performance of $\mathrm{CHI}$ respectively and Table 4 shows the results. From the perspective of a single configuration, there are three configurations to achieve the high performance and not-high performance respectively, and the consistencies of all configurations are greater than 0.9 , higher than 0.8 , the set threshold, which indicates that the analysis result of every single configuration is reliable. As a whole, the overall consistency of the three configurations to achieve high performance is 0.904 , and that of the three configurations to achieve nothigh performance is 0.975 . Both are higher than the generally accepted level, 0.8 . The overall coverage of the high performance and not-high performance is 0.648 and 0.519 respectively. Coverage refers to the extent to which the result can be explained by configurations, similar to determinable coefficient in econometrics.

Solution 1 shows a TOE strategy. It has four high conditions, the configuration with the most high-level conditions. At the same time, it has high conditions in any aspect of TOE. Therefore, the configuration is the most comprehensive and balanced path for high performance. Specifically, a combination of high $\mathrm{Tl}$, TMC, GA, and EA is sufficient for high performance. As shown by solution 1 , the raw coverage (0.319), it explains a high percentage of the high performance.

Solution 2 represents a $G A-E A-C D$ strategy. $\mathrm{CHI}$ can bring about high performance using high GA combined with high EA and high $\mathrm{CD}$. High EA and high $\mathrm{CD}$ demonstrate that $\mathrm{CHI}$ faces positive growth environment and has abundant potential demand. Meanwhile, high GA means that government departments pay close attention to the growth of $\mathrm{CHI}$ in the process of technology promotion. As a market regulator, government plays a great role in promoting, because it can not only cooperate with the invisible hand to solve the market failure but also act as an accelerator, formulate industry standards and 
introduce policy guidance. The solution' s raw coverage is 0.293 , accounting for approximately a third of the high performance.

In solution 3, the paper identifies a dual EA-CD strategy. This study finds that area can achieve high performance of $\mathrm{CHI}$ by purchasing high $\mathrm{EA}$ and high $\mathrm{CD}$ stragety when faced with not-high $\mathrm{FS}$. The core conditions of solution 2 and solution 3 are the same and they are called second-order equivalent configuration. The configuration has no other present conditions, indicating that the environment plays an important role in the promotion of $\mathrm{CHI}$. Solution 3's raw coverage is 0.42 , the largest of the three raw coverages, explaining a substantial share of the high $\mathrm{CHI}$ performance.

QCA regards correlation as the intersection of driving force and event result, and it has the characteristics of asymmetry [36]. Therefore, the configurations of not-high performance of $\mathrm{CHI}$ are not the negation of the configurations of high performance. The result is shown in Table 4.

Solution 4 represents a $T M C-E A-C D$ strategy. Environmental conditions EA and $C D$ are absent, indicating that the demand for $\mathrm{CHI}$ is weak and the current social environment is not suitable enough for the promotion. Although CD can be boosted by policy, it is difficult for EA to be enhanced. With the presence of $\mathrm{TI}$, the absence of TMC will affect the efficiency of technology promotion. Solution 4's raw coverage is very low, just 0.11 , indicating it explains a small-scale of the not-high performance.

Solution 5 shows a TI-EA strategy. High GA implies that government play an active role in promoting the development of $\mathrm{CHI}$ by making full use of relevant policies to allocate resources, such as tax incentives, financial subsidies. But only those authority behaviors cannot accomplish the high performance without the presence of $\mathrm{TI}$ and $\mathrm{EA}$. TI, the material carrier of practical technology application, plays a relatively passive role in the formation of high-performance $\mathrm{CHI}$, but is very necessary. $\mathrm{TI}$ and $\mathrm{EA}$ are the most important hardware and software for technology promotion which can be seen from the results of conditional necessity analysis (Table 2): EA and $\mathrm{TI}$ are the two conditions with the highest consistency $(0.806$ and 0.677$)$ respectively. Solution 5 explains a significant amount of the outcome (raw coverage $=$ 0.433).

Solution 6 identifies a TI-TMC-EA strategy, a second-order equivalent configuration of solution 5 . The two technological conditions TI and TMC in this solution are not present, indicating that there is a serious problem with the supply of technology. The outcome of not-high performance can be said to be mainly caused by technical problems. High CD means that the technology has a great potential demand, but due to the unsuitable social environment (not-high EA), the potential demand cannot be converted into normal demand. The solution's raw coverage is not big, at 0.164 , explaining a small part of the not-high $\mathrm{CHI}$ performance outcome.

Through the comprehensive analysis of the six pathways, severe key points are obtained. In three pathways of high-performance EA is present, but EA is absent in those of not-high performance. The paper can conclude that EA is a relatively more important than other conditions to achieve high 
performance for $\mathrm{CHI}$. This study makes a conservative conclusion that it is not considered as a necessary condition. Because EA's consistency, at 0.806 , is below the threshold value, 0.9 , and its effect size is just a little more than 0.1 , the threshold value. There are not a good theory helpful to consider it as one necessary condition, either. FS in all the three pathways of high-performance does not play a positive role and is even absent in the pathways, so FS has a negative effect on the promotion of $\mathrm{CHI}$. There are numerous studies about the effect of FS on healthcare insurance, and the effect is divided into three categories, positive, negative, and complex[60-62]. Those studies were mostly based on the conventional quantitative analysis, but the papers using QCA, like this study, are still deficient.

To check the robustness of analysis of sufficient condition, this study increases the threshold values of consistency with a proportional reduction in inconsistency by 0.05 ; that is, the two critical values are set to 0.85 and 0.8 respectively in this study and then the analysis was repeated [63]. The resulting configurations showed in Table 5, should be a subset of the previous configurations. Solution 1 in Table 5 is the true subset of solution 1 in Table 4, and other solutions are the same as those in Table 4, which shows that the analysis result is robust.

\section{Analysis of conditional substitution relationship}

Through the comparison between the various configurations of high-performance $\mathrm{CHI}$, this study finds out the substitution relationships between the conditions. First of all, through the comparison of solution 1 and solution 2, it is found that TI plus TMC can replace each other with CD when GA and EA are present simultaneously. In addition, the adjoint of TI, TMC, and GA can replace each other with that of the negations of FS and CD with the presence of EA by the comparison of solution 1 and solution 3. Finally, comparing solution 2 with solution 3, this study can identify that GA can replace with the negation of FS and vice versa when both EA and CD present simultaneously.

The three substitutions would support two viewpoints. First, technological conditions (TI and TMC) and EA are relatively important than other conditions. Technical conditions have strong flexibility in substitution relationships that these can substitute organizational conditions or environmental conditions under certain circumstances, in which the importance lies. The importance of EA focuses on the establishment of the three substitute relations based on the presence of the condition. Second, the negative effect of $\mathrm{FS}$ on the promotion of $\mathrm{CHI}$ is confirmed again. That results from the substitution relationship that GA can replace each other with the negation of FS with the presence of EA and $C D$, and is consistent with the above analysis of sufficient condition.

\section{Discussion}

This study innovatively constructs an analysis framework based on TOE theory, and firstly uses fs / QCA to analyze how technology, organization, and environment constitute the promotion path of $\mathrm{CHI}$ of China from the perspective of configuration. Three main conclusions are drawn. First, there is no necessary relationship between any condition and high or not-high performance of $\mathrm{CHI}$. But there are three sufficient configurations, the TOE strategy, GA-EA-CD strategy, and dual EA-CD strategy, to achieve high 
performance, and another three, TMC-EA-CD strategy, TI-EA strategy, and TI-TMC-EA strategy, to reach nothigh performance. Second, technological conditions (TI and TMC) and EA are relatively more important than other conditions. The importance of technological conditions lies in the strong flexibility in substitution relationship, and EA is the necessity for high performance and substitute relations. Third, it is proved that the financial expenditure of government departments has a negative effect on the development of $\mathrm{CHI}$.

The marginal contribution of this study is reflected in the following three aspects. First, fs/QCA method is used to analyze the driving paths of high performance of the promotion of $\mathrm{CHI}$ from the perspective of configuration and the substitution relationship between the conditions. Besides, the driving paths of the not-high performance are analyzed from the perspective of causal asymmetry[36]. The existing researches about $\mathrm{CHI}$ only focus on the independent effect of one factor, which analyze the relationship between some factors and $\mathrm{CHI}$ by regression and other quantitative methods. While this study firstly obtains such a result through configuration analysis by using fs/QCA.

Second, the integrated analysis framework based on TOE theory in the field of technology adoption is proposed, which is helpful to identify the promotion path of the development of $\mathrm{CHI}$ from the perspective of technology adoption. In addition, the analysis framework incorporates characteristics of China and special situation in China, which helps better understand the macro situation and influencing factors of $\mathrm{CHI}$. Therefore, the intrinsic effect of empirical research is enhanced. Meantime, the application of TOE theory is also extended. The TOE theory is used to find the influencing factors of an organization's adoption of innovative technology [28]. At most, the framework was used to analyze the adoption of general information technology [30]. By expanding the technical connotation, other things like technology can also be analyzed well, such as business model [31, 64], innovation decision [29], usage of audit [65]. Introducing TOE into health insurance has an important theoretical implication.

Third, the analysis from the perspective of configuration also promotes the development of TOE theory. The paper empirically discusses the concurrent synergistic effect and linkage matching mode of the multiple conditions (technology, organization, and environment) in the TOE framework to promote $\mathrm{CHI}$, further expanding the application of the TOE framework to explain causal complexity. The TOE framework has long been widely used to explain technology adoption in organizations. However, most studies have discussed the "marginal net effect" of a condition of technology, organization, or environment applying statistical regression. In addition, few studies have carefully examined the potential of linkage and matching of multiple conditions to influence the application level of technology. Furthermore, the relative importance of the role of multiple conditions is rarely discussed in an integrative analytical framework. At this level, this study is helpful to reveal the "black box" of multiple conditions in the TOE framework affecting the technology application level, and further deepen researchers' understanding of the complex mechanism behind the technology application.

Despite the best efforts, there are still some shortcomings in this study. First of all, although the configuration analysis has a more comprehensive and systematic understanding of the driving paths of 
$\mathrm{CHI}$, it still has some defects. First, calibration and counterfactual analysis in the QCA method is highly subjective which is difficult to avoid completely. Therefore, research conclusions depend on researchers' understanding of the research topic to a certain extent, which affects the accuracy of the conclusions. Second, QCA to study the promotion of $\mathrm{CHI}$ has just started, and the combination of other quantitative methods with this method can further improve the study design. Third, with an abduction logic, fs/QCA has an advantage of extending theory based on necessary and sufficiency causality $[66,67]$. So, this configurational finding can be complemented by future studies using deduction logic to test causal complexity. Fourth, having more cases in this study is better. The number of cases can limit the conditions contained in fS/QCA studies, and possible configurations increase exponentially with the number of conditions contained. Future research can examine more complex settings involving additional cases, strategies, and operating conditions. Fifth, temporal effect has been not integrated in the study. All the cases used are from the same year, cross section data, so these cannot reveal dynamism and turbulence. Therefore, temporal effect in a QCA framework is analyzed, a key point for future studies. Finally, this study is the first to apply the technology adoption theory to $\mathrm{CHI}$, which is an exploratory study, and there is no relevant theory to evaluate the adaptability of the TOE framework.

\section{Conclusion}

There are configurations or pathways to achieve high or not-high performance of promoting $\mathrm{CHI}$ and key factors are identified successfully. The paper has some practical implications for governments. First, each region should choose the driving path suitable for itself, instead of making homogenization policies and replicating policies of regions with high performance. In addition, the government should track the changes in the development level and conditions of $\mathrm{CHI}$ after the implementation of the policy, and adjust the policy accordingly. Second, TC and EA as key factors should be overcome. Technical conditions are relatively easy to achieve, but EA is more difficult, so the governments of areas of not-high EA can increase investment in social security to prevent residents' health risks. Third, although FS can crowd out $\mathrm{CHI}$ in some cases, it also has a pull effect. From the point of view of protecting the health of the people, they should not be regarded as the competition relationship, but the development of the two should be viewed from the perspective of the system as a whole. Therefore, the governments should formulate policies to systematically evaluate social insurance and $\mathrm{CHI}$ simultaneously and promote their coordinated development.

\section{Abbreviations}

$\mathrm{CHI}$

commercial health insurance; QCA:Qualitative Comparative Analysis; UEBMI:the Urban Employee Basic Medical Insurance; NCMS:the New Cooperative Medical Scheme; WHO:The World Health Organization; TOE:Technology-Organization-Environment; TI:technological infrastructure; TMC:technological management capability; GA:government attention; FS:financial support;EA:environment adaptability; 
CD:citizen demand; NCA:Necessary Condition Analysis; CIRC:the China Insurance Regulatory Commission; CR:Ceiling regression; $\mathrm{CE}$ :Ceiling envelopment.

\section{Declarations}

\section{Ethics approval and consent to participate}

Not applicable

\section{Consent for publication}

Not applicable

\section{Availability of data and materials}

The datasets used and/or analysed during the current study are available from the corresponding author on reasonable request.

\section{Competing interests}

The authors declare that they have no competing interests.

\section{Funding}

This research was funded by the Research Project of Macao Polytechnic Institute"Research on the comprehensive social benefits of promoting high quality economy under the new development concept",grant number RP/ESCHS-04/2020.

\section{Authors' contributions}

$\mathrm{XH}$ and $\mathrm{XX}$ were responsible for conceptualization, methodology, formal analysis and resources. TZ and $\mathrm{XH}$ were responsible for data curation, writing-original draft preparation, writing-review and editing. TZ was responsible for supervision, project administration and funding acquisition. All authors read and approved the final version of the manuscript.

\section{Acknowledgements}

Not applicable

\section{References}

1. Liu K. Insuring against health shocks: Health insurance and household choices. Journal of Health Economics 2016, 46:16-32. https://doi.org/10.1016/j.jhealeco.2016.01.002.

2. Rosenzweig MR, Wolpin KI. Credit Market Constraints, Consumption Smoothing, and the Accumulation of Durable Production Assets in Low-Income Countries: Investments in Bullocks in 
India. Journal of Political Economy 1993, 101(2):223-244. http://DOI.org/10.1086/261874.

3. Khan F, Bedi AS, Sparrow R. Sickness and Death: Economic Consequences and Coping Strategies of the Urban Poor in Bangladesh. World Development 2015, 72:255-266. https://doi.org/10.1016/j.worlddev.2015.03.008.

4. Kochar A. Explaining Household Vulnerability to Idiosyncratic Income Shocks. The American Economic Review 1995, 85(2):159-164. https://www.jstor.org/stable/2117911.

5. Geng X, Janssens W, Kramer B, van der List M. Health insurance, a friend in need? Impacts of formal insurance and crowding out of informal insurance. World Development 2018, 111:196-210. https://doi.org/10.1016/j.worlddev.2018.07.004.

6. Miller G, Pinto D, Vera-Hernández M. Risk Protection, Service Use, and Health Outcomes under Colombia's Health Insurance Program for the Poor. American Economic Journal: Applied Economics 2013, 5(4):61-91. https://doi.org/10.1257/app.5.4.61.

7. Azam M. Does Social Health Insurance Reduce Financial Burden? Panel Data Evidence from India. World Development 2018, 102:1-17. https://doi.org/10.1016/j.worlddev.2017.09.007.

8. Pan J, Tian S, Zhou Q, Han W. Benefit distribution of social health insurance: evidence from china's urban resident basic medical insurance. Health Policy and Planning 2016, 31(7):853-859. https://doi.org/10.1093/heapol/czv141.

9. Liu J, Chen H, Chen Y, Li Z. Exploring the relationship between migrants' purchasing of commercial medical insurance and urbanisation in China. BMC Health Services Research 2018, 18(1):679. https://doi.org/10.1186/s12913-018-3503-1.

10. Xu XC, Huang XQ, Zhang XL, Chen LH. Family Economic Burden of Elderly Chronic Diseases: Evidence from China. Healthcare 2019, 7(3). https://doi.org/10.3390/healthcare7030099.

11. Alwan A. Global Status Report on Noncommunicable Diseases 2010: World Health Organization; 2011.

12. Yu H. Universal health insurance coverage for 1.3 billion people: What accounts for China's success? Health Policy 2015, 119(9):1145-1152. https://doi.org/10.1016/j.healthpol.2015.07.008.

13. Liu X, Mills A. Financing reforms of public health services in China: lessons for other nations. Social Science \& Medicine 2002, 54(11):1691-1698. https://doi.org/10.1016/S0277-9536(01)00337-9.

14. Pan J, Liu GG. The determinants of chinese provincial government health expenditures: evidence from 2002-2006 data. Health Economics 2012, 21(7):757-777. https://doi.org/10.1002/hec.1742.

15. Innocenti S, Clark GL, McGill S, Cuñado J. The effect of past health events on intentions to purchase insurance: Evidence from 11 countries. Journal of Economic Psychology 2019, 74:102204. https://doi.org/10.1016/j.joep.2019.102204.

16. Asgary A, Willis K, Taghvaei AA, Rafeian M. Estimating rural households' willingness to pay for health insurance. European Journal of Health Economics 2004, 5(3):209-215. https://10.1007/s10198004-0233-6. 
17. Pollack,H., Kronebusch K. Health Insurance and Vulnerable Populations. In: Health Policy and the Uninsured. edn. Edited by McLaughlin CG; 2005: 205. http://www.rwjf-eriu.org/pdf/wp5.pdf.

18. Chang TY, Huang W, Wang Y. Something in the Air: Pollution and the Demand for Health Insurance. The Review of Economic Studies 2018, 85(3):1609-1634. https://doi.org/10.1177/0007650317703648.

19. Acland D, Levy MR. Naiveté, Projection Bias, and Habit Formation in Gym Attendance. Management Science 2015, 61(1):146-160. https://doi.org/10.1287/mnsc.2014.2091.

20. Zhao K. Social insurance, private health insurance and individual welfare. Journal of Economic Dynamics \& Control 2017, 78:102-117. https://doi.org/10.1016/j.jedc.2017.03.004.

21. Strombom BA, Buchmueller TC, Feldstein PJ. Switching costs, price sensitivity and health plan choice. Journal of Health Economics 2002, 21(1):89-116. https://doi.org/10.1016/S01676296(01)00124-2.

22. Hill RV, Kumar N, Magnan N, Makhija S, de Nicola F, Spielman DJ, Ward PS. Ex ante and ex post effects of hybrid index insurance in Bangladesh. Journal of Development Economics 2019, 136:117. https://doi.org/10.1016/j.jdeveco.2018.09.003.

23. Dragos SL, Mare C, Dragota IM, Dragos CM, Muresan GM. The nexus between the demand for life insurance and institutional factors in Europe: new evidence from a panel data approach. Economic Research-Ekonomska Istrazivanja 2017, 30(1):1477-1496. https://doi.org/10.1080/1331677X.2017.1325764.

24. Koo JE, Lim BH. Consumption and life insurance decisions under hyperbolic discounting and taxation. Economics Modelling 2021, 94:288-295. https://doi.org/10.1016/j.econmod.2020.10.003.

25. Sugawara S, Nakamura J. Gatekeeper incentives and demand inducement: An empirical analysis of care managers in the Japanese long-term care insurance program. Journal of the Japanese and International Economies 2016, 40:1-16. https://doi.org/10.1016/j.jjie.2016.03.001.

26. Jensen N, Stoeffler Q, Fava F, Vrieling A, Atzberger C, Meroni M, Mude A, Carter M. Does the design matter? Comparing satellite-based indices for insuring pastoralists against drought. Ecological Economics 2019, 162:59-73. https://doi.org/10.1016/j.ecolecon.2019.04.014.

27. Nieizviestna OV, Slobodyanyuk NO, Voloshyna SV, Gudz YF. The Research of Investment Capacity of Non-Banking Financial Institutions of Ukraine during Financial and Economic Crisis. Financial and Credit Activity-Problems of Theory and Practice 2019, 3(30):379-390. https://doi.org/10.18371/fcaptp.v3i30.179813.

28. Tornatzky LG, Fleischer,M. The Processes of Technological Innovation. Lexington,MA: Lexington Books; 1990. https://agris.fao.org/agris-search/search.do?recordID=US201300694725.

29. Hue TT. The determinants of innovation in Vietnamese manufacturing firms: an empirical analysis using a technology-organization-environment framework. Eurasian Business Review 2019, 9(3):247267. https://doi.org/10.1007/s40821-019-00125-w.

30. Nwankpa JK, Merhout JW. Exploring the Effect of Digital Investment on IT Innovation. Sustainability 2020, 12(18). https://doi.org/10.3390/su12187374. 
31. Mkansi M. E-business adoption costs and strategies for retail micro businesses. Electronic Commerce Research 2021. https://doi.org/10.1007/s10660-020-09448-7.

32. Hai DP, Roig-Dobon S, Sanchez-Garcia JL. Innovative governance from public policy unities. Journal of Business Research 2016, 69(4):1524-1528. https://doi.org/10.1016/j.jbusres.2015.10.135.

33. Huarng $\mathrm{KH}, \mathrm{Yu}$ THK. The impact of surge pricing on customer retention. Journal of Business Research 2020, 120:175-180. https://doi.org/10.1016/j.jbusres.2020.07.043.

34. Llopis-Albert C, Merigo JM, Xu YJ, Liao HC. Application of Fuzzy Set/Qualitative Comparative Analysis to Public Participation Projects in Support of the EU Water Framework Directive. Water Environment Research 2018, 90(1):74-83. https://doi.org/10.2175/106143017X15054988926550.

35. Delmas MA, Pekovic S. Organizational Configurations for Sustainability and Employee Productivity: A Qualitative Comparative Analysis Approach. Business \& Society 2018, 57(1):216-251. https://doi.org/10.1177/0007650317703648.

36. Ragin CC. Redesigning Social Inquiry: Fuzzy Sets and Beyond: University of Chicago Press; 2008.

37. Ragin CC, Strand SI. Using Qualitative Comparative Analysis to Study Causal Order: Comment on Caren and Panofsky. Sociological Methods \& Research 2008, 36(4):431-441. https://doi.org/10.1177/0049124107313903.

38. Ragin C. The Comparative Method: Moving Beyond Qualitative and Quantitative Strategies. In., vol. University of California Press; 1987. https://doi.org/10.2307/1972971.

39. Fainshmidt S, Witt MA, Aguilera RV, Verbeke A. The contributions of qualitative comparative analysis (QCA) to international business research. Journal of International Business Studies 2020, 51(4):455466. https://doi.org/10.1057/s41267-020-00313-1.

40. Du Y, Kim PH. One size does not fit all: Strategy configurations, complex environments, and new venture performance in emerging economies. Journal of Business Research 2021, 124:272-285. https://doi.org/10.1016/j.jbusres.2020.11.059.

41. Fiss PC. Building Better Causal Theories: A Fuzzy Set Approach to Typologies in Organization Research. Academy of Management Journal 2011, 54(2):393-420. https://doi.org/10.5465/amj.2011.60263120.

42. Pradhan RP, Dash S, Maradana RP, Jayakumar M, Gaurav K. Insurance market density and economic growth in Eurozone countries: the granger causality approach. Financial Innovation 2017, 3(1). https://doi.org/10.1186/s40854-017-0065-x.

43. Liu XP, Zheng H, Yang Y, Wang Q. Analysis of Factors Affecting China's Cargo Insurance Demand Based on E-commerce Background. Journal of Electronic Commerce in Organizations 2019, 17(1):16-29. https://10.4018/JEC0.2019010102.

44. Blomqvist $\AA$, Léger PT. Information asymmetry, insurance, and the decision to hospitalize. Journal of Health Economics 2005, 24(4):775-793. https://doi.org/10.1016/j.jhealeco.2004.12.001.

45. Dillender M, Friedson A, Gian C, Simon K. Does the healthcare educational market respond to shortrun local demand? Economics of Education Review 2019, 73.

https://doi.org/10.1016/j.econedurev.2019.101932. 
46. Sengupta R, Rooj D. The effect of health insurance on hospitalization: Identification of adverse selection, moral hazard and the vulnerable population in the Indian healthcare market. World Development 2019, 122:110-129. https://doi.org/10.1016/j.worlddev.2019.05.012.

47. Aleskerova Y, Kovalenko L, Havryliuk V. Innovative financial criteria for methodological approaches to the assessment of agrarian insurance. Baltic Journal of Economic Studies 2019, 5(4):34-41. https://doi.org/10.30525/2256-0742/2019-5-4-34-41.

48. Mare C, Dragos SL, Dragota IM. The impact of human development on the Romanian life insurance market: A county spatial econometric analysis. Cogent Business \& Management 2019, 6(1). https://doi.org/10.1080/23311975.2019.1707609.

49. Mare C, Dragos SL, Dragota IM, Dragos CM. Insurance Literacy and Spatial Diffusion in the Life Insurance Market: A Subnational Approach in Romania. Eastern European Economics 2019, 57(5):375-396. https://doi.org/10.1080/00128775.2019.1618194.

50. Perrino T, Lombard J, Rundek T, Wang KF, Dong CH, Gutierrez CM, Toro M, Byrne MM, Nardi MI, Kardys $\mathrm{J}$ et al. Neighbourhood greenness and depression among older adults. British Journal of Psychiatry 2019, 215(2):476-480. https://doi.org/10.1192/bjp.2019.129.

51. Riumallo-Herl C, Aguila E. The effect of old-age pensions on health care utilization patterns and insurance uptake in Mexico. BMJ Global Health 2019, 4(6). http://dx.doi.org/10.1136/bmjgh-2019001771.

52. Schneider CQ, Wagemann C. Doing Justice to Logical Remainders in QCA: Moving Beyond the Standard Analysis. Political Research Quarterly 2013, 66(1):211-220. https://www.jstor.org/stable/23563605.

53. Ragin CC. Fuzzy-Set Social Science: University of Chicago Press; 2000. https://press.uchicago.edu/ucp/books/book/chicago/F/bo3635786.html.

54. Wurster S, Hagemann C. Two ways to success expansion of renewable energies in comparison between Germany's federal states. Energy Policy 2018, 119:610-619. https://doi.org/10.1016/j.enpol.2018.04.059.

55. Yamasaki S, Rihoux B. A Commented Review of Applications. In: Configurational Comparative Methods: Qualitative Comparative Analysis (QCA) and Related Techniques. Edited by Rihoux B, Ragin CC. Thousand Oaks, California: SAGE Publications, Inc.; 2009. https://dx.doi.org/10.4135/9781452226569.n6.

56. Duşa A. QCA with R: A comprehensive resource: Springer; 2018. https://www.springer.com/gp/book/9783319756677\#aboutBook.

57. Dul J. Identifying single necessary conditions with NCA and fsQCA. Journal of Business Research 2016, 69(4):1516-1523. https://doi.org/10.1016/j.jbusres.2015.10.134.

58. Dul J. Necessary Condition Analysis (NCA): Logic and Methodology of "Necessary but Not Sufficient" Causality. Organizational Research Methods 2016, 19(1):10-52. https://doi.org/10.1177/1094428115584005. 
59. Dul J, van der Laan E, Kuik R. A Statistical Significance Test for Necessary Condition Analysis. Organizational Research Methods 2020, 23(2):385-395. https://doi.org/10.1177/1094428118795272.

60. Blumberg LJ, Dubay L, Norton SA. Did the Medicaid expansions for children displace private insurance? An analysis using the SIPP. Journal of Health Economics 2000, 19(1):33-60. https://doi.org/10.1016/S0167-6296(99)00020-X.

61. Kronick R, Gilmer T. Insuring Low-Income Adults: Does Public Coverage Crowd Out Private? Health Affairs 2002, 21(1):225-239. https://doi.org/10.1377/hlthaff.21.1.225.

62. Gruber J, Simon K. Crowd-out 10 years later: Have recent public insurance expansions crowded out private health insurance? Journal of Health Economics 2008, 27(2):201-217. https://doi.org/10.1016/j.jhealeco.2007.11.004.

63. Ordanini A, Parasuraman A, Rubera G. When the Recipe Is More Important Than the Ingredients: A Qualitative Comparative Analysis (QCA) of Service Innovation Configurations. Journal of Service Research 2013, 17(2):134-149. https://doi.org/10.1177/1094670513513337.

64. Widuri R, O'Connell B, Yapa PWS. Adopting generalized audit software: an Indonesian perspective. Managerial Auditing Journal 2016, 31(8/9):821-847. https://doi.org/10.1108/MAJ-10-2015-1247.

65. Li H, Dai J, Gershberg T, Vasarhelyi MA. Understanding usage and value of audit analytics for internal auditors: An organizational approach. International Journal of Accounting Information Systems 2018, 28:59-76. https://doi.org/10.1016/j.accinf.2017.12.005.

66. Douglas EJ, Shepherd DA, Prentice C. Using fuzzy-set qualitative comparative analysis for a finergrained understanding of entrepreneurship. Journal of Business Venturing 2020, 35(1):105970. https://doi.org/10.1016/j.jbusvent.2019.105970.

67. Furnari S, Crilly D, Misangyi VF, Greckhamer T, Fiss PC, Aguilera R. Capturing Causal Complexity: Heuristics for Configurational Theorizing. Academy of Management Review 2020. https://doi.org/10.5465/amr.2019.0298.

\section{Tables}

Table 1 Sets and calibrations. 


\begin{tabular}{|c|c|c|c|c|}
\hline Sets & Conditions & $\begin{array}{l}\text { Fully } \\
\text { out }\end{array}$ & Crossover & $\begin{array}{l}\text { Fully } \\
\text { in }\end{array}$ \\
\hline Outcome & $\begin{array}{l}\text { the performance of commercial health } \\
\text { insurance }\end{array}$ & 0.18 & 0.244 & 0.307 \\
\hline \multirow{2}{*}{$\begin{array}{l}\text { Technological } \\
\text { conditions }\end{array}$} & technological infrastructure $(\mathrm{TI})$ & 26 & 59 & 92 \\
\hline & $\begin{array}{l}\text { technological management capability } \\
\text { (TMC) }\end{array}$ & 553.5 & 1000 & 1446.5 \\
\hline \multirow{2}{*}{$\begin{array}{l}\text { Organizational } \\
\text { conditions }\end{array}$} & government attention (GA) & 1381 & 837 & 293 \\
\hline & financial support (FS) & 6.91 & 7.96 & 9.01 \\
\hline \multirow{2}{*}{$\begin{array}{l}\text { Environmental } \\
\text { conditions }\end{array}$} & environment adaptability (EA) & 53.38 & 59.52 & 65.66 \\
\hline & citizen demand (CD) & 9.655 & 11.246 & 12.837 \\
\hline
\end{tabular}

Table 2

Analysis of necessary conditions for high and not-high $\mathrm{CHI}$ performance in fs/QCA.

\begin{tabular}{|lllll|}
\hline \multirow{2}{*}{ Sets of conditions } & \multicolumn{2}{l}{ high performance } & \multicolumn{2}{l|}{ not-high performance } \\
\cline { 2 - 5 } & Consistency & Coverage & Consistency & Coverage \\
\hline TI & 0.677 & 0.697 & 0.382 & 0.416 \\
\hline TI & 0.433 & 0.398 & 0.722 & 0.703 \\
\hline$\sim$ TMC & 0.666 & 0.681 & 0.39 & 0.422 \\
\hline GA & 0.435 & 0.402 & 0.705 & 0.691 \\
\hline$\sim$ GA & 0.621 & 0.474 & 0.732 & 0.592 \\
\hline FS & 0.466 & 0.621 & 0.35 & 0.494 \\
\hline$\sim F S$ & 0.416 & 0.362 & 0.768 & 0.707 \\
\hline EA & 0.663 & 0.729 & 0.308 & 0.358 \\
\hline$\sim$ EA & 0.806 & 0.857 & 0.246 & 0.277 \\
\hline CD & 0.32 & 0.286 & 0.873 & 0.826 \\
\hline$\sim$ CD & 0.627 & 0.601 & 0.476 & 0.483 \\
\hline Note: $\sim$ means the absence of. & & 0.606 & 0.632 \\
\hline
\end{tabular}


Table 3

Results of Necessary-Condition Analyses (NCA).

\begin{tabular}{|lllllll|}
\hline Condition & Method & Accuracy & Ceiling zone & Scope & Effect size & P-value \\
\hline TIs & CE & 1 & 0.021 & 0.994 & 0.021 & 0.004 \\
\cline { 2 - 3 } & CR & 0.742 & 0.256 & 0.994 & 0.258 & 0.001 \\
\hline TM & CE & 1 & 0.029 & 0.992 & 0.03 & 0.013 \\
\cline { 2 - 3 } & CR & 0.871 & 0.023 & 0.992 & 0.023 & 0.08 \\
\hline FS & 1 & 0 & 0.961 & 0 & 1 \\
\hline EA & CR & 1 & 0 & 0.961 & 0 & 1 \\
\hline CD & 1 & 0 & 0.998 & 0 & 0.009 \\
\hline & CR & 1 & 0 & 0.998 & 0 & 0.008 \\
\hline & CR & 1 & 0.135 & 1 & 0.135 & 0 \\
\hline & CE & 1 & 0.291 & 1 & 0.291 & 0 \\
\hline
\end{tabular}

Notes: (1) NCA procedures are taken directly from J Dul [58].囚Membership scores are used instead of values in raw variables.

Due to technical limitations, table 4,5 is only available as a download in the Supplemental Files section.

Figures 


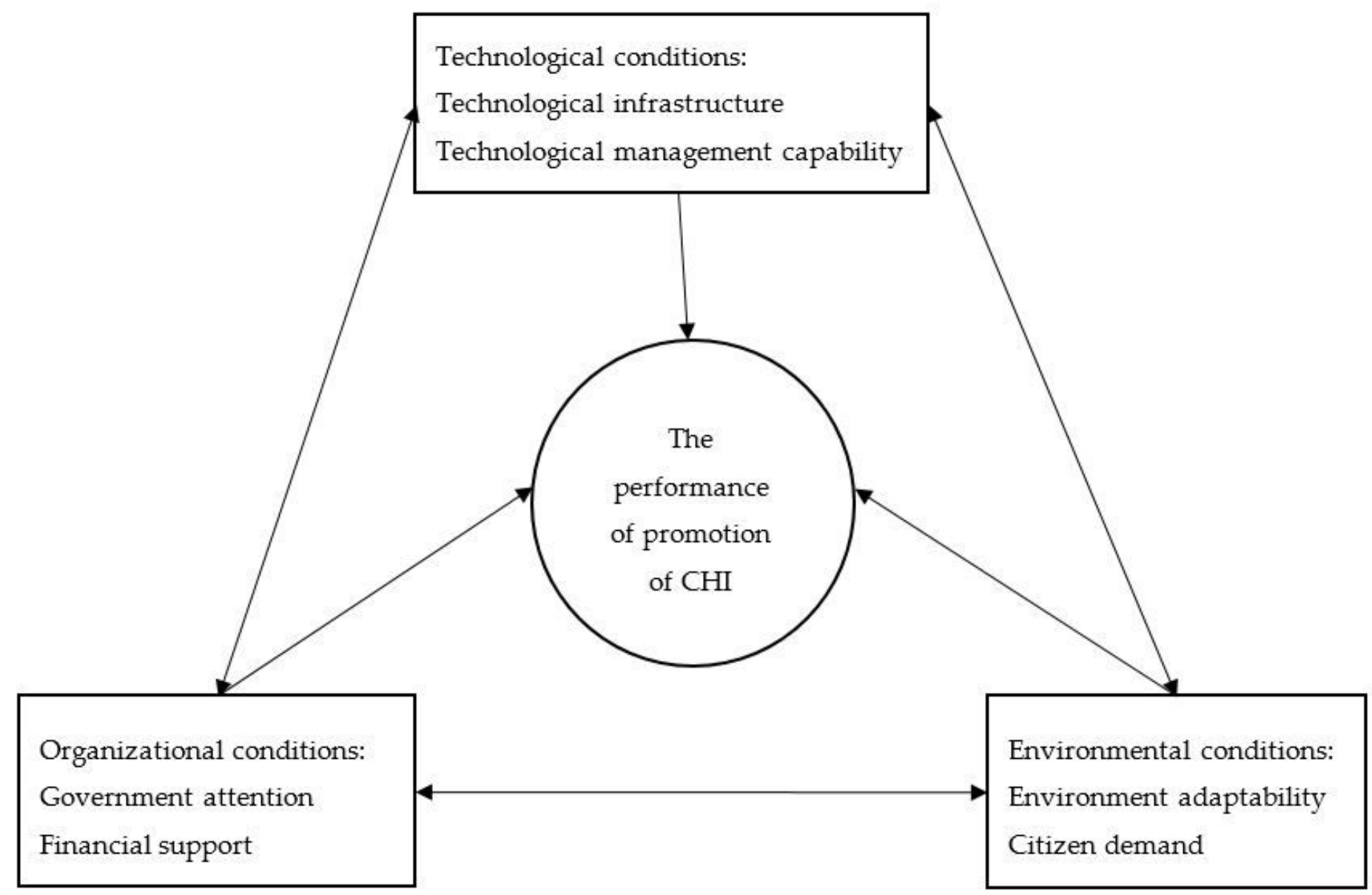

Figure 1

the TOE framework for the promotion of $\mathrm{CHI}$

\section{Supplementary Files}

This is a list of supplementary files associated with this preprint. Click to download.

- Table5.jpg

- Table4.jpg 